\title{
Viewpoints on Accreditation from Health Education Professionals and Administrators of Academic Professional Preparation Programs
}

\author{
Jay M. Bernhardt ${ }^{1}$, Donna M. Videto ${ }^{2}$, Christine L. Widdall ${ }^{2}$, W. William Chen $^{3}$, \\ Collins Airhihenbuwa ${ }^{4}$, and John P. Allegrante ${ }^{5}$ \\ ${ }^{1}$ Emory University Rollins School of Public Health \\ ${ }^{2}$ State University of New York, Cortland \\ ${ }^{3}$ University of Florida \\ ${ }^{4}$ Pennsylvania State University \\ ${ }^{5}$ Teachers College, Columbia University
}

\begin{abstract}
The health education profession has made significant strides in promoting quality assurance for credentialing of health educators through a combination of individual certification and program approval and accreditation mechanisms. Although the profession has widely embraced individual certification, program accreditation has not been uniformly accepted nor implemented. The National Task Force on Accreditation in Health Education was charged to develop a detailed plan for a coordinated accreditation system for undergraduate and graduate programs in health education. One of the goals of the task force was to gather professionwide input into any proposed new system. We conducted two Web-based surveys to assess viewpoints on accreditation and program approval from health education professionals $(\mathrm{n}=506)$ and from faculty and administrators at academic programs in health education $(n=105)$. Results from the surveys show that the majority of professionals in the field and at academic programs surveyed supported and would participate in a national, coordinated, professionwide accreditation system in health education. Furthermore, the majority of respondents suggested that the accreditation system should be comprehensive, flexible, build on the strengths of existing accreditation systems, and be linked to individual certification. Findings from these surveys, along with other input from the field, will help inform the final recommendations of the task force.
\end{abstract}

(c) 2004 Californian Journal of Health Promotion. All rights reserved.

Keywords: accreditation, program approval, health education profession, professional preparation

Concern over the quality of professional preparation and the promotion of standards for the professional preparation of health educators first appeared in the early 1940s when the American Public Health Association (APHA) began accrediting schools of public health (Boatman, Levin, Roberts, \& Rugen, 1966; Cleary, 1995; Creswell, 1981). Almost 20 years later, the Society for Public Health Education (SOPHE) published its "Statement of Functions of Community Health Educators and Minimum Requirements for their Professional Preparation, with Recommendations for Implementation" (SOPHE, 1977a), which provided guidelines to universities and community employers on the role of community health educators. In 1969 APHA's Committee on Professional Education published the first criteria and guidelines for accrediting graduate programs in community health education and, later, began accrediting graduate programs in community health education (APHA, 1969).

In 1974 the responsibility for accreditation of health education programs shifted from APHA to the Council on Education for Public Health $(\mathrm{CEPH})$. Using criteria for accreditation at the graduate level, CEPH now accredits health education graduate programs within schools of public health and outside schools of public 
health that offer the master of public health $(\mathrm{MPH})$ or other equivalent degrees. Baccalaureate-level programs in community health education have been eligible for "program approval” since 1980 using guidelines developed by SOPHE (1977b). In 1984 SOPHE and the American Association for Health Education (AAHE) joined to sponsor a unified undergraduate review process, which is now implemented through the SOPHE/AAHE Baccalaureate Program Approval Committee (SABPAC).

Since 1988 an AAHE and National Council for Accreditation of Teacher Education (NCATE) partnership largely conducts the accreditation of academic professional preparation programs in school health education, which are often located in schools of education and schools of health and human performance. The entry-level competencies in health education are among the core criteria for program review under both the AAHE/NCATE and SABPAC review processes; however, the process of implementing graduatelevel competencies in the review of professional preparation programs for school health education is still being developed.

According to the 2001 AAHE Directory of Institutions (AAHE, 2001), there are currently 233 professional preparation programs in health education. Of these programs, 1 is at the associate level, 92 (40\%) offer only baccalaureate degrees, 40 (17\%) offer only graduate degrees, and 100 (43\%) offer both baccalaureate and graduate degrees. Of the 123 (46\%) programs that have accreditation or program approval, 24\% have accreditation from NCATE/AAHE, 20\% have accreditation from $\mathrm{CEPH}$, and 9\% have approval from SABPAC.

Although the health education profession has made significant strides over the last two decades to strengthen credentialing through individual certification, and although more than $90 \%$ of academic programs indicate that they prepare students in the health education core competencies (Schwartz, O’Rourke, Eddy, Auld, \& Smith, 1999), accreditation of health education professional preparation programs has been neither uniformly implemented nor accepted. Existing health education accreditation systems encourage quality assurance from those who participate, but they lack coordination, are underutilized, and are undervalued by some within and outside of the profession (SOPHE \& AAHE, 2000). Moreover, anecdotal evidence suggests that many professionals have questioned the application of existing accreditation approaches to all types of academic programs. Professional preparation in health education must provide the health education specialist with knowledge and skills that form a foundation of common and settingspecific competencies (National Task Force on Accreditation, 2002). It is clear that any coordinated accreditation approach must also accommodate a diverse range of academic programs, each with its own unique history, perspective, and areas of emphasis.

In response to recent calls from professional health education organizations to explore coordinated accreditation (National Commission for Health Education Credentialing \& Coalition of National Health Education Organizations, 1995), the National Task Force on Accreditation in Health Education, sponsored by SOPHE and AAHE, was charged in 2000 to develop a detailed plan for a coordinated accreditation system for undergraduate and graduate programs in health education. One of the goals of the task force was to gather professionwide input on accreditation preferences and priorities to inform the development of a coordinated system. To gather input and feedback from health education professionals and students, and from faculty and administrators from academic programs in health education, the task force conducted two Web-based surveys that assessed current viewpoints on accreditation and program approval for graduate and undergraduate programs in health education. This article reports the results of these surveys and discusses the implications of these findings for moving forward with the development of a plan for a coordinated system of accreditation.

\section{Methods}

\section{Procedures for Survey 1}

The first survey was designed and administered to collect feedback from health education 
professionals throughout the United States. Data were collected over the Internet using a Webbased survey that was hosted on a server at the State University of New York at Cortland. When users visited the survey Web page, they were shown text describing the objective of the survey, a description of the population of interest, clarification of terms and definitions, instructions, the 20-item survey itself, and a concluding paragraph thanking them for their time and participation. In addition, consent information was provided on the instrument with directions that indicated submission of the completed survey implied a willingness to participate in the investigation. Respondents received no additional incentives for completing the survey. The Human Subjects Research Review Committee of the Office of Sponsored Programs at the hosting institution approved the instrument and research protocol. After completion of the survey, all survey data were automatically stored in a secure area with-in the college server. File transfer protocol was utilized with multiple passwords for restricting access to the data. All quantitative data were organized, cleaned, and imported into SPSS for analyses.

\section{Subjects for Survey One}

Respondents were recruited for the Web-based survey through paper advertisements distributed at the fall 2001 meetings of professional associations, direct e-mail invitations sent to members and section leaders from professional associations, and through online advertisements with links to the survey that were placed on several professional health education association Web sites. The Web sites hosting the ads and links included AAHE, SOPHE, the Public Health Education and Health Promotion Section of APHA, and the American School Health Association. Online ads and links also appeared on the electronic listserver of the Health Education Directory (HEDIR) and the Web site of the CNHEO. Self-reported inclusion criteria for respondents included being a health education or health promotion professional or student and/or belonging to a professional health education association. The survey was made available online beginning in September 2001 and remained accessible until late November 2001.

\section{Measures for Survey 1}

The development of the online survey instrument was facilitated by the Profession Committee of the National Task Force on Accreditation, with input from other task force committees and members. The final instrument, which was pilot tested with six health professionals representing various sites of practice, contained 18 close-ended and 2 openended questions that were divided into six sections. The first section assessed demographic items including current position, years of professional experience, and highest degree obtained. These questions were administered using pull-down lists of response choices. Section two assessed accreditation or program approval status of respondents' current/former professional preparation program and respondents' current worksite, and used pulldown response lists and clickable radio-button multiple-choice questions. Section three assessed respondents' intention to attend or work at an unaccredited or unapproved academic program and used radio-button yes/no questions with open-ended comment boxes. Section four assessed the perceived value of accreditation and perceived commitment to seeking accreditation, and answer choices included 4-point Likert-type responses ranging from Not at all valuable to Very valuable. The fifth section included questions on the certified health education specialist (CHES) credential and the credentialing process and used yes/no questions with comment boxes and pull-down lists of response choices. The last section included 2 open-ended questions to collect feedback on accreditation and the survey.

\section{Procedures for Survey 2}

The second online survey was designed and administered to collect feedback from academic professionals, including deans, chairs, program heads, and/or faculty at health education professional preparation programs in the United States. Data for this survey were collected over the Internet using a Web-based survey hosted and administered by Zoomerang, a company that specializes in online surveys and data collection. Completed survey data were stored automatically in a secure online 
database and were downloaded for analyses in SPSS. Respondents received no additional incentives for completing the survey. Informed consent was not collected from survey respondents prior to data collection because of the professional service nature of the survey, and because the data were not originally intended for scholarly dissemination. However, prior to the preparation and submission of this article for publication, approval for the dissemination of these anonymous data was obtained from the Institutional Review Board at Emory University.

\section{Subjects for Survey 2}

Respondents were recruited for the Web-based survey through direct e-mail invitations with a link to the survey that was signed by the task force chairs. These e-mails were generated by staff at SOPHE and AAHE and were sent respectively to e-mail address lists of 40 and 64 selected department and/or program chairs from academic health education programs. All recipients of each message were unique, with the exception of one person who received both messages; therefore, the message was sent to 103 recipients. The presence of the survey also was disseminated by word-of-mouth between academic professionals, by forwarded e-mails from original recipients to other appropriate respondents, and by Internet links placed on the SOPHE and AAHE Web sites. The survey was made available in mid-September 2001 and remained accessible until late October 2001.

\section{Measures for Survey 2}

The development of this online survey instrument was facilitated by the Academic Program Committee of the National Task Force on Accreditation, with input from other task force committees and members. In addition, a preliminary version of the survey was reviewed at the department chairs' meeting at the AAHE annual meeting in 2001 to generate the most frequent responses to questions that were used in the subsequent multiple-choice response options. The final online survey contained 20 closeended and 5 open-ended questions. The closeended questions included items about respondents' title and institution using pulldown response choices, the degrees currently being offered and current accreditation or program approval status using clickable yes/no radio buttons, and perceptions about their accreditation/approval status using 4-point Likert-type response choices that ranged from Not at all important to Very important. In addition, survey items assessed the perceived benefits, barriers, and potential resources for participating in a coordinated accreditation system, and questions about important characteristics that this new system should possess. These questions used multianswer multiple-choice questions and pull-down lists from which respondents could select one answer. The open-ended questions on this survey explored additional benefits, barriers, and suggestions about accreditation. No individual demographic data were collected from respondents on either survey, and all survey questions on both surveys were treated as singleitem indicators in data analysis.

\section{Results}

\section{Respondents to Survey 1}

A total of 506 respondents completed the online survey. Of these respondents, nearly all (96\%) reported having earned a master's degree or higher as the highest degree they had obtained. A majority of the participants (61\%) reported having graduated from an accredited or approved program, whereas $24 \%$ were unaware of their program accreditation or approval status. About half of the respondents who reported being eligible for CHES (51\%) indicated that they currently held the credential, and 5\% were not aware of the existence of CHES.

About two-thirds of the respondents (67\%) reported that they currently worked as health educators. The most common work setting reported by the respondents was a university or college (23\%), followed closely by public health education (22\%). Of the 120 respondents who reported working at a college or university, 26\% reported working as a health educator, 66\% indicated they were faculty member or instructors, and $8 \%$ indicated that they were administrators. Three-quarters of the respondents reported working for at least 4 years in the health education or health promotion field. 


\section{Perceptions of Accreditation and Certification from Survey 1}

Overall, most respondents reported that they find accreditation and/or program approval to be valuable for health education professional preparation programs. The vast majority (90\%) indicated that accreditation or approval is very valuable or somewhat valuable for academic health education programs. Almost seven of eight of the respondents (85\%) reported that accreditation or approval would be somewhat valuable or very valuable for health educators

working in a higher education setting, and 83\% indicated a willingness to commit their own time or resources toward achieving accreditation. Although $64 \%$ of respondents indicated that they would accept a position at an unaccredited academic program, almost three-fourths (72\%) indicated that they would not accept admission into an unaccredited institution or program for their own studies (Table 1). These findings did not significantly differ by respondent position, job title, years of experience, or professional association membership.

Table 1

Accreditation Beliefs and Intentions Among Health Education Professionals

\begin{tabular}{|l|c|c|}
\hline & Yes & No \\
\hline Accreditation is important $(\mathrm{n}=491)$ & $87 \%$ & $13 \%$ \\
\hline Would commit time toward accreditation $(\mathrm{n}=442)$ & $83 \%$ & $17 \%$ \\
\hline Would accept position at unaccredited program $(\mathrm{n}=480)$ & $64 \%$ & $36 \%$ \\
\hline Would accept admission to unaccredited program $(\mathrm{n}=481)$ & $28 \%$ & $72 \%$ \\
\hline
\end{tabular}

When asked about the value of the CHES credential, nearly three-fourths (74\%) reported that CHES is somewhat or very important to the profession. Seventy-eight percent supported the importance of linking CHES credentialing to program accreditation, and the majority (54\%) indicated that these linkages should occur at both the undergraduate and graduate levels. In addition, almost half (47\%) of respondents suggested that completing a degree from an accredited program should automatically qualify the graduate to sit for the CHES exam, and 29\% suggested that graduating from an accredited program should automatically provide CHES certification without the need for taking an exam. These findings did not statistically significantly vary by respondent position, job title, years of experience, or professional association membership.

\section{Qualitative Feedback from Survey 1}

More than 100 statements were provided on the open-ended items seeking additional thoughts or comments for the task force. A review of these data revealed the presence of several frequently mentioned themes. Many respondents stated that accreditation is essential for health education professional preparation programs, and that this process is critical for ensuring uniform quality of programs. For example, one respondent noted that "accreditation of programs is absolutely vital to the success of our profession." Other respondents commented on how accreditation needs to be marketed as an attractive option to academic programs, administrators, and to students as well. For example, one respondent suggested that the target force should "get letters out to every college dean and university administrator" to inform them of the value of accreditation. Although the majority of responses discussed the benefits of accreditation, a number of respondents raised concerns about obtaining "buy-in" from the people in power at their institutions. Other concerns raised included the potential of limited resources, both time and money, to negatively impact a new accreditation process.

\section{Respondents to Survey 2}

A total of 105 respondents completed the online survey. More than one-third of the respondents (35\%) indicated that they were department heads or chairpersons; $35 \%$ reported being program directors or coordinators; $22 \%$ were faculty 
members; 6\% were deans, associate deans, or assistant deans; and $2 \%$ served in other positions. Because the original survey solicitation letter was sent to department chairs with an option of forwarding the message to others who were most appropriate to complete the survey, all responses were considered in data analysis. More than three-fourths of the respondents $(78 \%)$ indicated that they worked at public universities, $16 \%$ were from private universities, $4 \%$ from public colleges, and $2 \%$ from private collages. Seventy-nine percent of the respondents reported that their departments offered degrees at the bachelor's level, 73\% offered degrees at the master's level, and 33\% offered doctorates.

Almost half (47\%) of the respondents reported that their program currently had accreditation from NCATE offered in conjunction with AAHE, one-third (33\%) reported having accreditation from CEPH, 10\% reported having program approval from SABPAC, and $27 \%$ reported having no accreditation or program approval. Almost 15\% reported having more than one accredited and/or approved program.

Perceptions of Accreditations and

\section{Certification from Survey 2}

Respondents from programs that were already accredited or approved were asked to rate the importance of their type of accreditation or approval. Among the respondents with NCATE/AAHE accreditation $(\mathrm{n}=48), \quad 58 \%$ reported possessing the accreditation as "very important," 38\% reported it was "somewhat important," and 4\% said it was "a little important." Among respondents from CEPHaccredited programs $(n=35), 86 \%$ reported it as "very important" and 14\% reported it to be "somewhat important." Among respondents from SABPAC-approved programs $(\mathrm{n}=10), 60 \%$ reported it as "very important," 30\% reported it to be "somewhat important," and 10\% said it was “a little important."

Overall, more than three-quarters of respondents (76\%) indicated an intention to participate in an "expanded, new, or combined" health education accreditation system. Respondents' desire to participate in this process differed significantly according to their existing accreditation/ approval status (chi-square=9.61, $\mathrm{p}<.05$ ). Eighty-four percent of respondents from NCATE/AAHE-accredited programs expressed a willingness to participate in a coordinated accreditation system, as did 70\% with $\mathrm{CEPH}$ accreditation, $100 \%$ with SABPAC approval, and $75 \%$ of the currently unaccredited/ unapproved programs (Figure 1).

The most frequently selected benefits of participating in a coordinated accreditation system were improving the reputation of the program (69\%), improving the quality of the program (52\%), attracting quality faculty (40\%), and increasing enrollment (36\%). Other frequently mentioned benefits included improving the quality (30\%) and quantity (25\%) of applicants and providing a justification for more resources, faculty, and support (7\%). The belief that participating would increase program reputation varied significantly based on the accreditation/approval status of respondent's institutions (chi-square $=21.0, \mathrm{p}<.001$ ). Ninety percent of respondents from SABPAC-approved programs felt participating in the coordinated accreditation system would increase their program reputation, compared with $87 \%$ of respondents from unaccredited/unapproved programs, $65 \%$ of respondents from NCATE/AAHE-accredited programs, and 37\% of respondents from CEPH-accredited programs. The benefit of improving program quality differed by the position of the respondent. Among faculty, $61 \%$ perceived this to be a benefit, compared with $49 \%$ of department heads, 38\% of program coordinators, and 33\% of deans, associate deans, and assistant deans, but these differences were not statistically significant (chi-square $=5.75, \mathrm{p}=.22$ ).

The most frequently selected barriers to participating in a coordinated accreditation system were the time it would take to participate (71\%), the cost of participating (70\%), and the challenge of having limited personnel resources (65\%). Other barriers that were mentioned included getting support from administrators (34\%), no clear benefits of participating (6\%), and lack of interest and support on campus (5\%). Perceived barriers did not differ significantly by 
program accreditation or approval status or job position of the respondent. The funding source that respondents indicated they would use for participating in a coordinated accreditation system were school- or college-level resources
(75\%), university-level resources (61\%), department resources (39\%), or other sources $(18 \%)$ such as a university foundation or a state legislature.

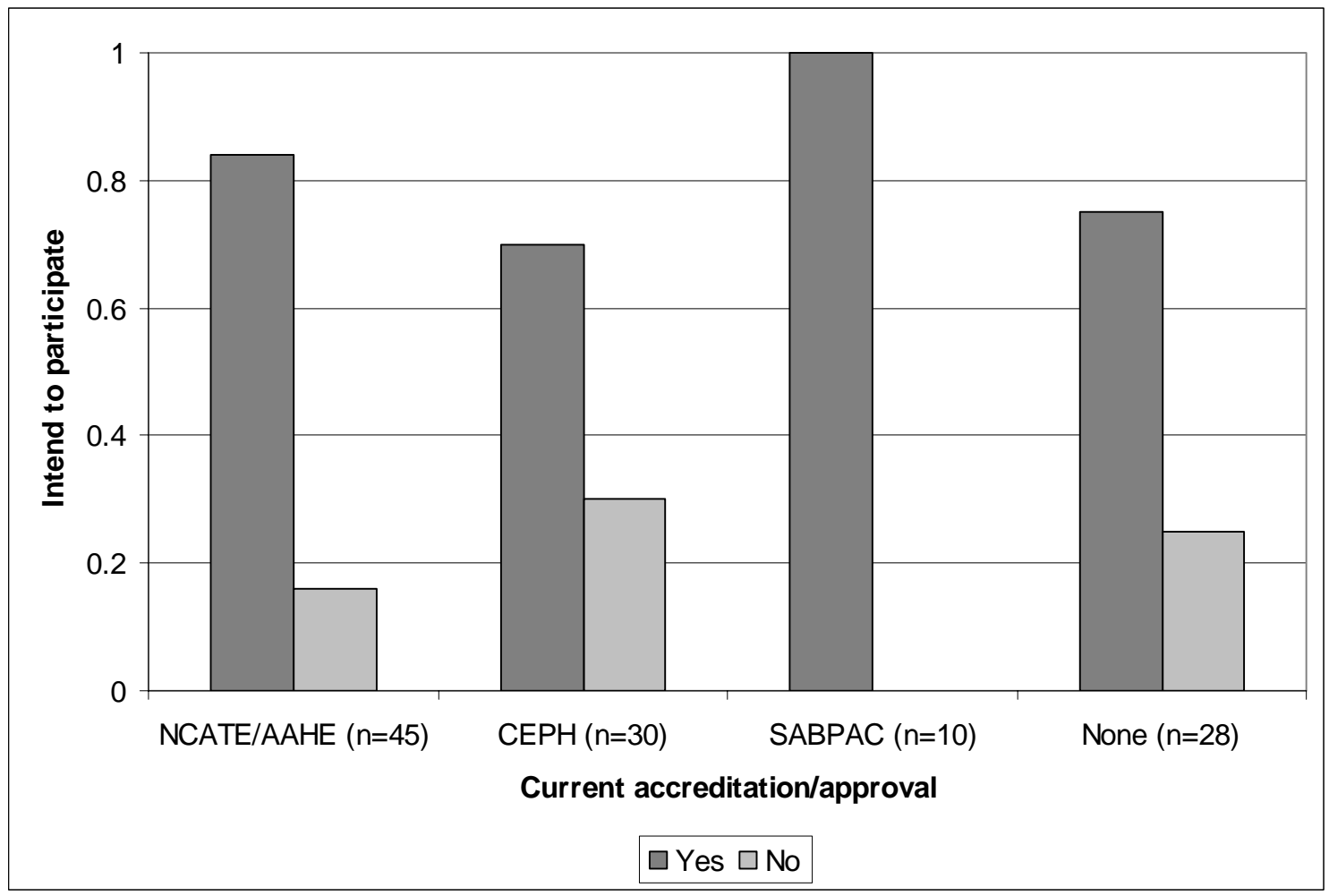

Figure 1

Intention to Participate in a Coordinated Accreditation System in Health Education by Current Accreditation/Approval Status of Program

When asked how important it would be to link a coordinated accreditation system to the existing accreditation and approval systems, more than half of the respondents (54\%) indicated that it would be "very important," 30\% said it would be "somewhat important," 8\% said "a little important," and 8\% said "not at all important." When asked about the importance of linking a coordinated accreditation system to individual credentialing (i.e., CHES), more than half (53\%) indicated that it should be linked at both the graduate and undergraduate levels, $10 \%$ said it should only be linked at the undergraduate level, $13 \%$ expressed no preference, and 21\% said it should not be linked. Preferences for linking accreditation to credentialing included the following: $45 \%$ of respondents preferred that completing an accredited program qualifies individuals to sit for the CHES exam; 26\% preferred that completing an accredited program automatically infers the CHES credential on the graduate; $18 \%$ preferred leaving the systems unlinked; and 11\% expressed other preferences.

\section{Qualitative Feedback from Survey 2}

A total of 160 specific comments were provided in response to open-ended survey questions. The comments largely addressed issues of benefits, 
barriers, funding sources, linkages, accreditation system characteristics, and additional feedback and ideas for the task force, some of which have been discussed here. Some major themes that emerged related to characteristics of a coordinated accreditation system and included flexibility to accommodate programs with different size faculties, different numbers of students, different goals and settings of emphasis, and differences of geography; ease of use to include a simple process with clear guidelines and expectations and a reasonable amount of paperwork; and piggy-backing the system on existing systems to ensure widespread buy-in.

\section{Discussion}

The primary goal of the surveys discussed in this article was to gather input from health education professionals, and from faculty and administrators from health education professional preparation programs to help inform the work of the National Task Force on Accreditation in Health Education. The quantitative and qualitative results from the two surveys suggest that both of the audiences surveyed attached high importance to accreditation for academic health education programs. Furthermore, both groups expressed strong inclination to participate in a coordinated accreditation system. Other important findings were that the majority of participants on both surveys felt the coordinated accreditation system should build on the highly regarded existing accreditations systems and that it should be linked to individual certification.

Nine of 10 respondents on the survey of health education professionals reported that accreditation of academic health education programs would be valuable for the profession. Similarly, more than $90 \%$ of respondents from accredited or approved academic programs reported that their accreditations/approval status was important. Overall, more than three-fourths of respondents from accredited/approved programs and unaccredited/unapproved programs expressed willingness to participate in a new coordinated accreditation system, although the levels of willingness varied somewhat by type of existing accreditation or approval. Similarly, more than three-fourths of the health education professionals reported that they would commit their own time and resources to the accreditation system, and nearly threefourths indicated that they would not personally accept admission into an unaccredited academic health education program. These findings demonstrate strong support for existing accreditation systems and for a coordinated accreditation system in health education as well.

The survey findings also suggest three characteristics that respondents felt were important to address with a new coordinated accreditation system in health education. First, the accreditation system should build on existing accreditation systems, both because they are considered important and also because it would diminish overlap in the new system, thereby making it more manageable and beneficial to participate. Second, the accreditation system should be coordinated and comprehensive, but also flexible enough to accommodate the wide diversity that exists in health education preparation programs, including diversity of location, resources, focus of work setting, instructional approach, faculty size, and so forth. Third, the coordinated accreditation system should be linked to the process of individuallevel credentialing, which has often received high marks from the profession. Previous research by Prelip (2001), for example, found that health education professionals with the CHES certification expressed high levels of job satisfaction and satisfaction with compensation, work, coworkers, and supervision.

Nearly three-fourths of the current survey respondents considered the CHES credential to be important to the health education profession, and more than three-fourths from the professional survey and the academic program survey indicated that it would be important to link accreditation to certification. The majority on both surveys felt that this link should occur at both the undergraduate and graduate levels. The linkage approach that received the most support on both surveys was that graduating from an accredited program should qualify the graduate to sit for the certification exam. The surveys did not explore whether respondents believed that 
graduating from an accredited program should be required for sitting for the certification exam.

The two surveys had several limitations that should be considered when interpreting these findings. First, the respondents to either survey represent convenience samples from the populations of professional health educators and faculty and administrators from health education professional preparation programs, respectively. Although efforts were made to solicit respondents through diverse means, it is entirely possible that these respondents were not representative of the populations from which they were drawn. For example, $96 \%$ of the respondents from Survey 1 reported having a master's degree, and 61\% reported graduating from an accredited program; but in 2001 only $60 \%$ of professional preparation programs offered graduate degrees, and only $46 \%$ of programs were accredited/approved (AAHE, 2001). Similarly, respondents to Survey 2, who came from programs accredited by NCATE/AAHE (47\%) and CEPH (33\%) and approved by SABPAC (10\%) were not entirely consistent with all academic health education programs, of which only $24 \%$ were accredited by NCATE/AAHE, $20 \%$ by CEPH, and $9 \%$ by SABPAC in 2001 (AAHE, 2001).

Second, all data collection and most recruitment efforts were conducted using the Internet, primarily through communication from professional associations. Although the penetration of the Internet is extremely high in professional and higher education communities, it is possible that this data collection approach may have excluded some individuals or programs, particularly those with fewer resources that do not have access to this technology.

Third, the concepts being assessed in these surveys, including accreditation and credentialing, are complex, not understood by many in the profession, and often erroneously used interchangeably. Although definitions and explanations of acronyms were included in the surveys, it is still possible that some respondents did not understand all of the concepts being measured, or that some potential respondents chose not to participate due to lack of knowledge on these topics. One lesson learned from this process is that additional education should be provided to health education professionals, especially while they are students, about these important issues and concepts.

Finally, because the questions on the surveys were collected and analyzed as single items rather than combined as scales or indices, there was no attempt to calculate or report reliability for the survey items. However, the surveys were closely reviewed and revised by multiple experts on the task force during development and were beta-tested online prior to deployment. To the extent that these surveys were unreliable, this could be a threat to the internal validity of the findings.

Despite these limitations, the results from these surveys provide an informative overview of the perceptions and preferences of professionals and academic program faculty and administrators in health education who responded to the surveys. Furthermore, the fact that the findings proved to be so consistent between both surveys provides some cautious validation for the findings and suggests that these beliefs may be more widely held in the populations of interest.

Gathering professionwide input about efforts to assure the quality of professional preparation programs is critical for the success of such efforts (Livingood \& Auld, 2001). The National Task Force on Accreditation in Health Education views the findings from these surveys, along with other input and feedback collected from individuals and organizations in the field in the past and in the future, as essential elements that will inform the work of the task force and the final recommendations that are issued. The task force understands that the only way a coordinated health education accreditation system can be successful at encouraging quality assurance of professional preparation in health education is if it is widely accepted and utilized, and if it reflects the needs and desires of the profession. The task force believes the lessons learned from these surveys can help us meet those objectives. 


\section{References}

American Association for Health Education. (2001). Directory of institutions offering undergraduate and graduate degree programs in health education. American Journal of Health Education, 32, 153168.

American Public Health Association. (1969). Committee on Professional Education: Criteria and guidelines for accrediting graduate programs in community health education. American Journal of Public Health, 59, 534-542.

Boatman, R. H., Levin, L. S., Roberts, B., \& Rugen, M. (1966). Professional preparation in health education in schools of public health. A report prepared for the 1965 Annual Meeting of the Association of Schools of Public Health. Health Education Monographs, 21, 1-35.

Cleary, H. P. (1995). The credentialing of health educators: An historical account 1970-1990. New York: National Commission for Health Education Credentialing.

Creswell, W. H. (1981). Professional preparation: An historical perspective. In U.S. Department of Health and Human Services (ed.), National conference for institutions preparing health educators (pp. 43-60). Washington, DC: Department of Health and Human Services.

Livingood, W. C., \& Auld, M. E. (2001). The credentialing of a population-based health profession: Lessons learned from health education certification. Journal of Public Health Management and Practice, 7, 38-45.

National Commission for Health Education Credentialing, \& Coalition of National Health Education Organizations. (1995). The health education profession in the twenty-first century: Setting the stage. Conference Proceedings, June 16-17, 1995, Atlanta, GA.

National Task Force on Accreditation in Health Education. (2002). Accreditation system for the health education profession: Statement of interim principles and recommendations. (Available from the Society for Public Health Education at 750 First St. NE, Suite 910, Washington, DC 20002, and the American Association for Health Education at 1900 Association Dr., Reston, VA 20191).

Prelip, M. L. (2001). Job satisfaction in health education and the value added of credentialing. American Journal of Health Education, 32, 26-30.

Schwartz, L. W., O’Rourke, T. W., Eddy, J. M., Auld, E., \& Smith, B. (1999). Use and impact of the competencies for entry-level health educators on professional preparation programs. Journal of Health Education, 30, 206-216.

Society for Public Health Education. Ad Hoc Task Force on the Professional Preparation and Practice of Health Education (1977a). Guidelines for the preparation and practice of professional health educators. Health Education Monographs, 5, 1, 75-89.

Society for Public Health Education. (1977b). Committee on Professional Preparation and Practice of Community Health Educators at the Baccalaureate Level. Health Education Monographs, 5, 1, 90-98.

Society for Public Health Education, \& American Association for Health Education. (2000). Future Directions for Quality Assurance of Professional Preparation in Health Education. [Meeting report]. Reston, VA: Joint meeting of SOPHE and AAHE.

\section{Acknowledgements}

The authors wish to acknowledge and thank all the members of the National Task Force on Accreditation in Health Education for their contributions to this work: Collins O. Airhihenbuwa, PhD, MPH, Pennsylvania State University (AAHE co-chair); John P. Allegrante, PhD, Columbia University (SOPHE co-chair); Evelyn E. Ames, MS, PhD, CHES, Western Washington University; Michael D. Barnes, PhD, CHES, Brigham Young University; Jay M. Bernhardt, PhD, MPH, Emory University; David Birch, PhD, CHES, Southern Illinois University; Rena Boss-Victoria, DrPH, MSN, Morgan State University; Ellen M. Capwell, PhD, CHES, Otterbein College; W. William Chen, PhD, CHES, University of Florida; Joan Cioffi, PhD, U.S. Centers for Disease Control and Prevention; Pat Evans, MPH, Council on Education for Public Health; Cezanne Garcia, MPH, CHES, University of Washington Medical Center; Audrey R. Gotsch, DrPH, CHES, University of Medicine and Dentistry of New Jersey; Mary E. Hawkins, MSPH, 
MEd, CHES, North Carolina Central University; William C. Livingood, Jr., PhD, Duval County Health Department, Florida; Kathleen Miner, PhD, MPH, CHES, Emory University; Henry Montes, MPH, Health Resources and Services Administration; Sheila M. Patterson, PhD, CHES, West Chester University; Kathleen Roe, DrPH, MPH, San Jose State University; Donna Videto, PhD, CHES, State University of New York, Cortland; Boyce Williams, PhD, National Council for Accreditation of Teacher Education; Elaine Auld, MPH, CHES, ex officio, SOPHE; and Becky J. Smith, PhD, ex officio, AAHE.

\section{$\underline{\text { Author Information }}$}

Jay M. Bernhardt, PhD, MPH, is with Rollins School of Public Health at Emory University, 1518 Clifton Road NE, Atlanta, GA 30322; E-mail: jbernha@sph.emory.edu.

Donna M. Videto, PhD, CHES, and Christine L. Widdall, MS, CHES, are with the Health Department at the State University of New York, College at Cortland, P.O. Box 2000, Courtland, NY 13045.

W. William Chen, PhD, CHES, is with the Department of Health Science Education, University of Florida, Gainesville, P.O. Box 118210, Gainesville, FL 32611.

Collins Airhihenbuwa, MPH, $\mathrm{PhD}$, is with the Department of Biobehavioral Health, Pennsylvania State University, 304 East Health \& Human Development, University Park, PA 16802.

John P. Allegrante, $\mathrm{PhD}$, is with the Department of Health and Behavior Studies at Teachers College, Columbia University, 525 West 120th St., Box 114, New York NJ, 10027

This article has been republished with permission from the American Journal of Health Education. The article was originally published in the AJHE November/December 2003 Issue, Volume 34, Number 6, Pages 351-358. 